\title{
HUBUNGAN STATUS GIZI DENGAN SIKLUS MENSTRUASI PADA REMAJA DI BANDAR LAMPUNG
}

\author{
Yuliati Amperaningsih*, Nurul Fathia* \\ *Jurusan Keperawatan Poltekkes Tanjungkarang
}

\begin{abstract}
Asupan gizi yang tidak ade kuat menyebabkan ketidakteraturan menstruasi pada kebanyakan remaja putri. Berhubungan dengan menstruasi jumlah wanita anovulasi akan meningkat apabila berat badannya mengalami perubahan (meningkat atau menurun). Presurvey yang dilakukan pada siswi disalah satu MAN di Bandar Lampung didapatkan $4(40 \%)$ siswi yang mengalami siklus menstruasi teratur dengan status gizi normal dan $6(60 \%)$ siswi mengalami siklus menstruasi tidak teratur, $3(30 \%)$ siswi diantaranya mengalami status gizi kurang dan $3(30 \%)$ siswi lainnya mengalami status gizi lebih (obesitas). Desain penelitian menggunakan observasional analitik dengan pendekatan Crosss Sectional. Jumlah populasi 161, menggunakan teknik proportional random sampling dengan cara simple random sampling, didapatkan sampel 62 responden. Alat pengumpul data menggunakan lembar observasi dan lembar kuesioner, menggunakan metode analisa chi square. Hasil penelitian dari 62 orang responden, diketahui bahwa sebagian besar responden memiliki status gizi normal yaitu 38 responden $(61,3 \%)$ dan mengalami siklus menstruasi teratur sebanyak 39 responden (62,9\%). Hasil uji statistik Chi Square dengan derajat kepercayaan $(\mathrm{CI}) 95 \%$ dan nilai $\alpha(0,05)$ didapatkan hasil perhitungan $\rho$ value $(0,01)<\alpha$ $(0,05)$ yang menunjukan bahwa ada hubungan bermakna antara status gizi dengan siklus menstruasi pada remaja di Bandar Lampung. Disarankan untuk dilakukan penyuluhan pada para remaja putri untuk lebih menjaga status gizinya agar memiliki siklus menstruasi yang teratur.
\end{abstract}

\section{Kata kunci : Status Gizi, Siklus Menstruasi}

\section{LATAR BELAKANG}

Status gizi masyarakat adalah salah satu indikator keberhasilan pembangunan di Indonesia. Pembangunan kesehatan bertujuan untuk meningkatkan kualitas sumber daya manusia (SDM), salah satu yang berperan dalam peningkatan kualitas SDM adalah gizi yang baik, terutama untuk peningkatan gizi remaja. ICRW (International Center for Research on Women) melalui penelitian dibeberapa negara, menemukan status gizi yang kurang pada remaja sebesar 23-53\% berdasarkan Indeks Massa Tubuh (IMT). IMT adalah salah satu cara penilaian status gizi seseorang. Status gizi dikatakan normal dengan perhitungan IMT/U menggunakan $\mathrm{Z}$ score $\geq 2,0 \mathrm{~s} / \mathrm{d} \leq 1,0$ untuk perempuan usia 5-18 tahun (Kemenkes RI, 2010). Status gizi remaja ini akan berdampak pada status gizinya di kemudian hari.

Kehidupan kesehatan reproduksi wanita di pengaruhi oleh beberapa faktor yang berpotensi menimbulkan gangguan. Salah satu faktor yang berpengaruh adalah status gizi. Ciri wanita yang mampu melakukan kehidupan reproduksi adalah telah menstruasi. Menstruasi yang berulang setiap bulan tersebut pada akhirnya akan membentuk siklus menstruasi (Cunningham, 2005). Asupan gizi yang tidak ade kuat menyebabkan ketidakteraturan menstruasi pada kebanyakan remaja putri (Chomaria, 2008). Pada status gizi lebih (overweight dan obesity) biasanya mengalami anovulatory chronic atau menstruasi tidak teratur secara kronis (Karyadi, 2007). Karena cenderung memiliki sel-sel lemak yang berlebih, sehingga memproduksi estrogen yang berlebih. Sedangkan pada status gizi kurang (underweight) akan terjadi kekurangan berat badan dan tidak mempunyai cukup sel lemak untuk memproduksi estrogen yang dibutuhkan untuk ovulasi dan menstruasi sehingga mengakibatkan siklus menstruasi tidak teratur (Evan, 2011).

Sebelumnya penelitian serupa pernah diangkat oleh Kamidah dan Isnaini, 2014 didapatkan hasil sebagian besar responden memiliki IMT normal (68\%) dan 
mengalami siklus menstruasi tidak teratur (62,0\%). Hasil uji statistik dengan Chi Square didapatkan nilai $p$ value $=0,035<$ 0,05 maka $\mathrm{H}_{0}$ ditolak dan $\mathrm{H}_{\mathrm{a}}$ diterima. Simpulan: Ada hubungan yang signifikan antara indeks massa tubuh dengan siklus menstruasi. Penelitian lain dilakukan oleh Nunung, 2017 hasil penelitian yang didapatkan adalah status gizi sebagian besar responden adalah normal yaitu 40 orang $(60,6 \%)$ dan paling sedikit dengan status gizi gemuk yaitu 6 orang $(9,1 \%)$. Siklus menstruasi sebagian besar responden adalah normal yaitu 42 orang $(63,6 \%)$ dan paling sedikit dengan siklus menstruasi tidak normal yaitu 24 orang (36,4\%). Hasil uji Kendall Tau didapatkan T 0,547 dengan signifikansi (p) 0,001 yang artinya ada hubungan antara status gizi dengan siklus menstruasi pada remaja putri di SMAN 1 Bantul Yogyakarta. Demikian juga penelitian yang telah dilakukan oleh Hamdani dan El Alasi, 2017 didapatkan hasil uji Chi-square untuk melihat hubungan variabel IMT dengan siklus menstruasi maka diperoleh hasil $p=0,001$ yang berarti terdapat hubungan yang bermakna antara IMT dengan keteraturan siklus menstruasi karena nilai $p$ yang didapatkan $<0,05$.

Menurut Coad (2007) menyebutkan status gizi memiliki peranan penting dalam siklus menstruasi. Diperlukan paling tidak $22 \%$ lemak dan indeks massa tubuh yang lebih besar $19 \mathrm{~kg} / \mathrm{m}^{2}$ agar siklus ovulatorik dapat terpelihara dengan normal. Hal ini dikarenakan sel-sel lemak melepaskan estrogen yang membantu ovulasi dan siklus menstruasi. Berhubungan dengan menstruasi, secara khusus jumlah wanita anovulasi akan meningkat apabila berat badannya mengalami perubahan (meningkat atau menurun) (Paath, 2005).

Berdasarkan studi pendahuluan yang dilakukan terhadap $10(100 \%)$ siswi kelas XI di salah satu MAN di Bandar Lampung pada tanggal peneliti menemukan $4(40 \%)$ siswi yang mengalami siklus menstruasi teratur dengan status gizi normal dan 6 $(60 \%)$ siswi mengalami siklus menstruasi tidak teratur, $3(30 \%)$ siswi diantaranya mengalami status gizi kurang dan 3 (30\%) siswi lainnya mengalami status gizi lebih (obesitas).

\section{METODE}

Rancangan penelitian adalah observasional analitik dengan pendekatan Cross Sectional. Populasi dalam penelitian ini adalah seluruh siswi kelas XI pada salah satu MAN di Bandar Lampung yang berjumlah 161 siswi dan sudah mengalami menstruasi lebih dari 2 tahun. Pengambilan sampel dengan menggunakan rumus Hasmer dan Klar didapatkan hasil 62 orang responden dengan besar penyimpangan $(d=0,05)$ dan tingkat kepercayaan $95 \%$.

Pengumpulan data menggunakan data primer yaitu data yang didapat langsung dari responden melalui kuesioner dan lembar observasi mengenai siklus menstruasi serta mengukur $\mathrm{BB}$ dan $\mathrm{TB}$ secara langsung untuk mengetahui IMT yang menjelaskan status gizi siswi. Sebelum responden mengisi lembar kuesioner, peneliti memberikan penjelasan tentang penelitian dan melakukan persetujuan dengan memberikan inform consent. Pengoahan data dengan cara editing, coding, processing cleaning. Analisis data univariat menggunakan distribusi frekuensi, sedangkan bivariat dengan uji statistic Chi Square.

\section{HASIL}

\section{Analisis Univariat}

Diketahui bahwa sebagian besar responden memiliki status gizi normal sebanyak 38 responden atau $61,3 \%$, status gizi kurang sebanyak 16 responden atau 25,8\%, 7 responden atau 11,3\% memiliki status gizi lebih dan 1 responden memiliki status gizi obesitas atau 1,6\%. Pada hasil yang didapatkan dari penilaian siklus menstruasi didapatkan hasil sebagian besar responden memiliki siklus menstruasi teratur sebanyak 39 responden atau $62,9 \%$ 
dan 23 responden tidak memiliki siklus menstruasi yang teratur.

\section{Analisa Bivariat}

Tabel 1: Hubungan Antara Status Gizi dengan Siklus Menstruasi

\begin{tabular}{lcccccc}
\hline \multirow{2}{*}{$\begin{array}{c}\text { Status Gizi } \\
\text { (IMT) }\end{array}$} & \multicolumn{3}{c}{ Siklus Menstruasi } & \multicolumn{2}{c}{ Total } \\
\cline { 2 - 5 } & \multicolumn{3}{c}{ Teratur } & \multicolumn{2}{c}{ Tidak } & \\
Teratur & f & $\%$ \\
\cline { 2 - 5 } & $\mathrm{f}$ & $\%$ & $\mathrm{f}$ & $\%$ & & \\
\hline IMT Normal & 31 & 81,6 & 7 & 18,4 & 38 & 100 \\
\hline IMT Kurang & 5 & 31,2 & 11 & 68,8 & 16 & 100 \\
\hline IMT Lebih & 3 & 42,9 & 4 & 57,1 & 7 & 100 \\
\hline IMT Obesitas & 0 & 0 & 1 & 100 & 1 & 100 \\
\hline Jumlah & 39 & 62,9 & 23 & 37,1 & 62 & 100 \\
\hline p-value= $=0,001$ & & & & & \\
\hline
\end{tabular}

Berdasarkan tabel di atas dapat dilihat bahwa dari 38 (100\%) responden yang memiliki status gizi dengan IMT normal yang mengalami siklus menstruasi teratur ada $31(81,6 \%)$ responden dan yang mengalami siklus menstruasi tidak teratur ada $7(18,4 \%)$ responden, sedangkan dari $16(100 \%)$ responden yang memiliki IMT kurang mengalami siklus menstruasi teratur sebanyak adalah $5 \quad(31,2 \%)$ responden dan $11(68,8 \%)$ responden lainnya mengalami siklus menstruasi tidak teratur, kemudian dari 7 (100\%) responden yang memiliki IMT lebih mengalami siklus menstruasi teratur adalah $3(42,9 \%)$ dan $4(57,1 \%)$ lainnya mengalami menstruasi tidak teratur, serta 1 (100\%) responden yang memiliki IMT obesitas dan mengalami siklus menstruasi tidak teratur dan $0 \quad(0 \%)$ responden yang memiliki IMT obesitas dan siklus menstruasi teratur.

Hasil uji statistik Status Gizi dengan Siklus Menstruasi dengan Chi Square dihasilkan perhitungan $\rho$ value $(0,01)<\alpha$ $(0,05)$ yang berarti ada hubungan yang bermakna antara Status Gizi dengan Siklus Menstruasi.

\section{PEMBAHASAN}

\section{Status Gizi pada Remaja}

Berdasarkan hasil penelitian menunjukkan bahwa sebagian besar responden memiliki status gizi dengan kategori IMT Normal yaitu sebanyak 38 responden. Hasil penelitian ini sesuai dengan penelitian yang dilakukan oleh Pratiwi (2011) yang berjudul hubungan status gizi dengan keteraturan siklus menstruasi siswi sma negeri 1 mojolaban, dengan hasil siswi yang memiliki status gizi normal dengan siklus menstruasi teratur sebanyak 33,3\% yang merupakan hasil terbesar dari status gizi kurus yang berjumlah $21,9 \%$ dan status gizi lebih berjumlah $6,6 \%$.

Bagi remaja, makanan merupakan suatu kebutuhan pokok untuk pertumbuhan dan perkembangan tubuhnya. Diperlukan zat-zat yang cukup agar pertumbuhan fisik dapat berlangsung dengan sempurna, baik dari segi kualitas maupun kuantitas (Paath, 2005). Arisman (2007) menyatakan bahwa tidak seimbangnya antara asupan dan keluaran energi mengakibatkan perubahan berat badan. Pengaruh lingkungan terutama gizi, lebih penting daripada latar belakang genetis atau biologis lain terutama dalam masa pertumbuhan.

Berdasarkan hasil penelitian pada tabel 4.1 secara umum status gizi responden adalah baik. .Suhardjo (2003) menyebutkan bahwa status gizi dipengaruhi oleh faktor sosial budaya dan agama yang kuat terhadap makanan pantang, penerimaan makanan dan kebiasaan makanan. Bagi remaja makanan adalah kebutuhan pokok untuk pertumbungan dan perkembangan tubuhnya. Diperlukan zat-zat gizi yang cukup agar pertumbuhan fisik dapat berlangsung dengan sempurna, baik dari segi kualitas maupun kuantitas (Paath, 2005).

Tempat penelitian ini adalah MAN 2 Bandar Lampung yang memiliki daerah stategis dan tidak terpencil dengan pola kebudayaan yang tidak banyak memiliki pantangan dan larangan makanan tertentu, sehingga zat-zat gizi yang dibutuhkan 
mampu dipenuhi dengan mudah. Kantinkantin yang tersedia di MAN 2 Bandar Lampung juga merupakan kantin yang dipilih dengan pertimbangan oleh pihak sekolah agar para siswa dan siswi tidak jajan sembarangan dan dapat menghindari jajanan yang tidak sehat. Kebiasaan membawa bekal dari rumah yang dilakukan sebagian siswi juga dapat mempengaruhi terjaganya gizi yang tepat untuk para siswi, karena disamping sehat juga pola makan para siswi akan terjaga dengan baik dan bisa menghindari makanan-makanan siap saji (junk food) yang kita tahu biasanya banyak mengandung MSG (Monosodium Glutamat).

\section{Siklus Menstruasi pada Remaja}

Berdasarkan hasil penelitian menunjukkan bahwa sebagian besar responden memiliki siklus menstruasi teratur sebesar $39(62,9 \%)$ responden. Hasil penelitian ini tidak sesuai dengan penelitian yang dilakukan oleh Prathita (2017) yang berjudul hubungan status gizi dengan siklus menstruasi pada mahasiswi fakultas kedokteran universitas andalas, yang mana didapatkan bahwa tidak ada hubungan antara IMT dengan keteraturan siklus menstruasi pada siswi fakultas kedokteran universitas andalas dengan $\mathrm{p}=0,77$ dimana responden overweight lebih banyak yang mengalami siklus menstruasi teratur sebanyak 20 responden dibandingkan dengan underweight terhadap ketidakteraturan menstruasi yang hanya sebanyak 2 responden.

Berbeda dengan teori yang dikemukakan oleh Kusmiran, (2011) bahwa siklus menstruasi dipengaruhi oleh beberapa faktor salah satunya satu gizi karena penurunan berat badan akut dan sedang menyebabkan gangguan pada fungsi ovarium, tergantung derajat tekanan pada ovarium dan lamanya penurunan berat badan. Kondisi patologis seperti berat badan yang kurus/kurang dan anorexia nervosa yang menyebabkan penurunan berat badan yang dapat menimbulkan amenorrhea. Dan apabila kelebihan berat badan terjadi gangguan metabolisme estrogen berupa peningkatan produksi estrogen pada wanita sehingga menyebabkan siklus tidak teratur.

Hal ini dimungkinkan ada faktor lain selain nutrisi yang mempengaruhi siklus menstruasi. Ada banyak faktor yang mempengaruhi siklus menstruasi antara lain aktifitas fisik, stress, serta penyakitpenyakit endokrin yang berhubungan langsung dengan gangguan menstruasi seperti diabetes, hipertiroid, serta hipotiroid. Prevalensi amenorrhea dan oligomenorhea lebih tinggi pada pasien diabetes. Sedangkan penyakit polycystic ovarium berhubungan dengan obesitas (Kusmiran, 2011). Namun dalam penelitian ini belum bisa diungkapkan semua faktor tersebut secara mendetail karena terbatasnya instrumen pengukuran dan alokasi waktu penelitian.

\section{Hubungan Status Gizi dengan Siklus Menstruasi}

Hasil penelitian mengungkapkan bahwa terdapat hubungan yang bermakna antara status gizi dengan siklus menstruasi pada remaja di Bandar Lampung. Hasil penelitian ini berbeda dengan penelitian sebelumnya yang dilakukan Dayanti (2004) dengan judul hubungan status gizi (indeks $\mathrm{BB} / \mathrm{U}$ ) dan frekuensi olahraga dengan pola siklus menstruasi pada siswi SMP 1 Galur Kabupaten Kulon Progo tahun 2004, uji korelasi pearson product moment diperoleh bahwa status gizi berdasar indeks $\mathrm{BB} / \mathrm{U}$ tidak memiliki hubungan signifikan terhadap pola siklus menstruasi dengan nilai $\mathrm{p}=0,427$ dan nilai $\mathrm{r}=0,121$.

Penelitian lain yang menunjukan hasil sama dengan peneliti dilakukan oleh Nunung (2017) dengan judul hubungan antara status gizi dengan siklus menstruasi pada remaja putri di SMAN 1 Bantul Yogyakarta. Hasil penelitian yang didapatkan status gizi sebagian besar responden adalah normal yaitu 40 orang $(60,6 \%)$ dan paling sedikit dengan status gizi gemuk yaitu 6 orang $(9,1 \%)$. Siklus menstruasi sebagian besar responden adalah normal yaitu 42 orang $(63,6 \%)$ dan paling sedikit dengan siklus menstruasi 
tidak normal yaitu 24 orang (36,4\%). Hasil uji Kendall Tau didapatkan T 0,547 dengan signifikansi (p) 0,001 yang artinya ada hubungan antara status gizi dengan siklus menstruasi pada remaja putri di SMAN 1 Bantul Yogyakarta.

Hal ini membuktikan bahwa status gizi mempengaruhi siklus menstruasi wanita yang sesuai dengan teori yang dikemukakan oleh Coad (2007), yang menyatakan diperlukan paling tidak $22 \%$ lemak dan IMT yang lebih besar $19 \mathrm{~kg} / \mathrm{m}^{2}$ agar siklus ovulatorik dapat terpelihara dengan normal, dikarenakan sel-sel lemak melepaskan estrogen yang membantu ovulasi dan siklus menstruasi. Gangguan menstruasi pada dasarnya berhubungan erat dengan adanya gangguan hormon terutama yang berhubungan dengan hormon seksual pada perempuan yaitu progesterone, estrogen, LH dan FSH. Adanya gangguan dan kerja sistem hormonal ini terkait pada status gizi. Dimana status gizi akan mempengaruhi metabolisme hormon estrogen pada sistem reproduksi wanita (Caroline, 2001). Seorang wanita yang mengalami kekurangan maupun kelebihan gizi akan berdampak pada penurunan fungsi hipotalamus yang tidak memberikan rangsangan kepada hipofisa anterior untuk menghasilkan FSH dan LH, dimana FSH ini berfungsi merangsang pertumbuhan sekitar 3-30 folikel yang masing-masing mengandung 1 sel telur. Tetapi hanya 1 folikel yang terus tumbuh, yang lainnya hancur. Sedangkan LH berfungsi dalam pematangan sel telur atau ovulasi (fase sekresi) yang nantinya jika tidak dibuahi akan mengalami peluruhan (menstruasi), sehingga apabila produksi FSH dan LH terganggu maka siklus menstruasi juga akan terganggu.

Berhubungan dengan menstruasi, secara khusus jumlah wanita anovulasi akan meningkat apabila berat badannya mengalami perubahan (meningkat atau menurun) (Paath, 2005). Soetjiningsih (2004) berpendapat bila obesitas pada anak terus berlanjut sampai dewasa akan mengakibatkan menstruasi tidak teratur. Namun seberapa gemuk yang akan menyebabkan siklus anovulasi tidak diketahui dengan pasti, yang jelas diet dan berat badan sangat mempengaruhi siklus menstruasi (Paath, 2005). Remaja perempuan yang mempunyai status gizi kurus sekali juga akan mengalami hambatan dengan menstruasinya. Kehilangan berat badan secara besarbesaran dapat menyebabkan penurunan gonadotropin untuk pengeluaran LH dan FSH yang mengakibatkan kadar estrogen akan turun sehingga berdampak negatif pada siklus menstruasi dan ovulasi. Sekresi LH yang terganggu akibat penurunan berat badan dapat menyebabkan pemendekan fase luteal (Coad, 2007).

Berdasarkan beberapa penelitian yang meneliti tentang hubungan status gizi dengan siklus menstruasi ada beberapa ketidaksesuaian yang dimungkinkan terjadi karena adanya perbedaan pada pemilihan sampel penelitian antara lain mahasiswi, siswi SMP dengan siswi SMA/MAN dimana jumlah unsur gizi yang perlukan tubuh berbeda sesuai umur seseorang. Selain itu tempat penelitian yang dilakukan memiliki perbedaan taraf gizi penduduk masing-masing daerah dan juga kemungkinan minimnya penyuluhan tentang kesehatan terutama kesehatan sistem reproduksi yang didapatkan oleh para remaja putri dan orang tua siswi tentang pentingnya status gizi yang akan mempengaruhi siklus menstruasi. Hal ini yang perlu kita sadarkan kepada para orang tua dan anaknya tentang dampak yang akan terjadi apabila seseorang mengalami siklus menstruasi yang tidak teratur secara terus menerus.

\section{KESIMPULAN}

Hasil penelitian menyimpulkan ada hubungan antara status gizi dengan siklus menstruasi pada pada remaja di Bandar Lampung dengan $\rho$-value $=0,001$.

Disarankan Bagi pihak sekolah bekerjasama dengan puskesmas setempat, maka perlu diadakan penyuluhan mengenai kesehatan reproduksi terutama tentang keteraturan siklus menstruasi, serta gizi 
seimbang yang baik untuk remaja. Penyuluhan diadakan sebaiknya dengan media elektronik sehingga membuat para siswi tertarik dan mengerti akan informasi yang akan disampaikan.

\section{DAFTAR PUSTAKA}

Arisman, (2007). Gizi Dalam Daur Kehidupan. Jakarta: EGC.

Caroline, dkk. 2001. Kesehatan Wanita Diatas Umur 40 Tahun. Jakarta. PT. Elex Media

Chomaria, N. (2008). Aku Sudah Gede (Ngobrolin Pubertas Buat Remaja Islam). (A. Najmuddin, Ed) Solo: Samudera.

Coad, Jane. (2007). Anatomi dan Fisiologi untuk Bidan. Jakarta: EGC

Cunningham, F G, dkk, (2005). Obsteri Wilianms Volume I. Jakarta: EGC

Dayanti, Wiwin. (2004) Hubungan Status Gizi (Indeks BB/U) dan Frekuensi Olahraga dengan Pola Siklus Menstruasi pada Siswi SMP 1 Galur Kabupaten Kulon Progo Tahun 2004.

Evan, (2011). Faktor-faktor Ketidakteraturan Siklus Menstruasi. Jakarta. Salemba Medika.

Hamdani, Irfan dr.,Sp.An. El Alasi, Zaki Yatun Usna. (2017) Hubungan Indeks Massa Tubuh (IMT) terhadap keteraturan siklus menstruasi pada Siswi Madrasah Aliah Negeri Dolok Masihul di Kecamatan Dolok Masihul, Program Pendidikan Dokter, Fakultas Kedokteran Universitas Muhammadiyah Sumatera Utara.
Kamidah, Isnaini. (2014) Hubungan Indeks Massa Tubuh dengan Siklus Menstruasi pada Siswi Kelas X di MAN Tempurasari Mantingan Ngawi, Sekolah Tinggi Ilmu Kesehatan 'Aisyiyah Surakarta.

Karyadi, E. (2007). "Menangkal Rasa Sakit Menjelang Haid”. (Online) (http://www.indomedia.com/intisari/ 1999/Mei/haid.htm diakses 2 Maret $\underline{2018)}$

Kusmiran, E. (2011). Kesehatan Reproduksi Remaja dan Wanita. Jakarta: Salemba Medika.

Nunung (2017). Hubungan antara Status Gizi dengan Siklus Menstruasi pada Remaja Putri di SMAN 1 Bantul Yogyakarta, Program Studi Ilmu Keperawatan, Sekolah Tinggi Ilmu Kesehatan Jendral Achmad Yani Yogyakarta.

Paath, E, F. (2005). Gizi dalam Kesehatan Reproduksi. Jakarta:EGC.

Prathita, Yana A. Syahredi. Lipoeto, Nur Indrawati. (2017) Hubungan Status Gizi dengan Siklus Menstruasi pada Mahasiswi Fakultas Kedokteran Universitas Andalas Tahun 2017.

Pratiwi, Audhia (2011) Hubungan Status Gizi denganKeteraturan Siklus Menstruasi Siswi SMA Negeri 1 Mojolaban, Program Studi D IV Kebidanan Fakultas Kedokteran Universitas Sebelas Maret Surakarta.

Suhardjo, (2003). Berbagai Cara Pendidikan Gizi. Jakarta: Bumi Aksara

Soetjiningsih, (2004). Tumbuh Kembang Remaja dan Permasalahannya. Jakarta: Sagung Seto. 